\title{
Integrated production and separation of furfural
}

\section{using an acidic-based aqueous biphasic system}

Eduarda S. Moraist, Nicolas Schaeffert*, Mara G. Freiret, Carmen S.R. Freire†, João

A. P. Coutinho ${ }^{\prime}$ and Armando J. D. Silvestre ${ }^{*}$

$\dagger C I C E C O$ - A veiro Institute of Materials, Department of Chemistry, University of

Aveiro, Campus Universitário de Santiago, 3810-193 Aveiro, Portugal

Number of pages: 19

Number of figures: 11

Number of Tables: 5 
Table S1. Tested conditions in the initial assays carried out in the Monowave 300 microwave.

\begin{tabular}{|c|c|c|c|c|}
\hline IL (wt.\%) & $\begin{array}{c}\text { HCl } \\
\text { (wt.\%) }\end{array}$ & $\begin{array}{c}\text { Temperature } \\
\left({ }^{\circ} \mathbf{C}\right)\end{array}$ & $\mathrm{S} / \mathrm{L}$ ratio & Time (min) \\
\hline 20,30 and 40 & 5 and 10 & $\begin{array}{c}110,120,130 \\
140,150\end{array}$ & 0.05 & $\begin{array}{l}1,2,2.5,3 \\
\quad \text { and } 4\end{array}$ \\
\hline
\end{tabular}

\section{Reaction Assays Results}

Furfural production assays in the $\mathrm{ABS}$ formed by the IL $\left[\mathrm{P}_{44414}\right] \mathrm{Cl}$ and $\mathrm{HCl}$ were initially carried out with conventional heating; however, and due to dissatisfactory furfural yields, microwave heating assays were conducted to increase furfural yield and to reduce the time of reaction, which in turn translate into lower furfural degradation.

Figure S1 reports the results of two assays conducted in the microwave reactor with fixed temperature and $\mathrm{HCl}$ concentration. These assays were performed to address the effect of the IL wt. $\%$ in the furfural yield and extraction efficiency to the IL-rich phase (top phase). All the assays were conducted in the biphasic region of the system, thus assuring a continuous furfural production and extraction to the IL-rich phase.

Considering that the biphasic strategy intends to separate the products to prevent undesirable side reactions, the evaluation of furfural extraction efficiency (EE\%) is key. The results attained reveal the increase in both furfural yield (from 26.6 to $33.4 \%$ ) and $\mathrm{EE} \%$ (from 82.2 to $87.0 \%$ ) when the IL wt.\% is increased from 20 to $30 \mathrm{wt} . \%$. This behavior is mostly correlated to an increase in size of the IL-rich phase, which decreases the phase saturation with furfural and thus furfural degradation in the aqueous phase. 


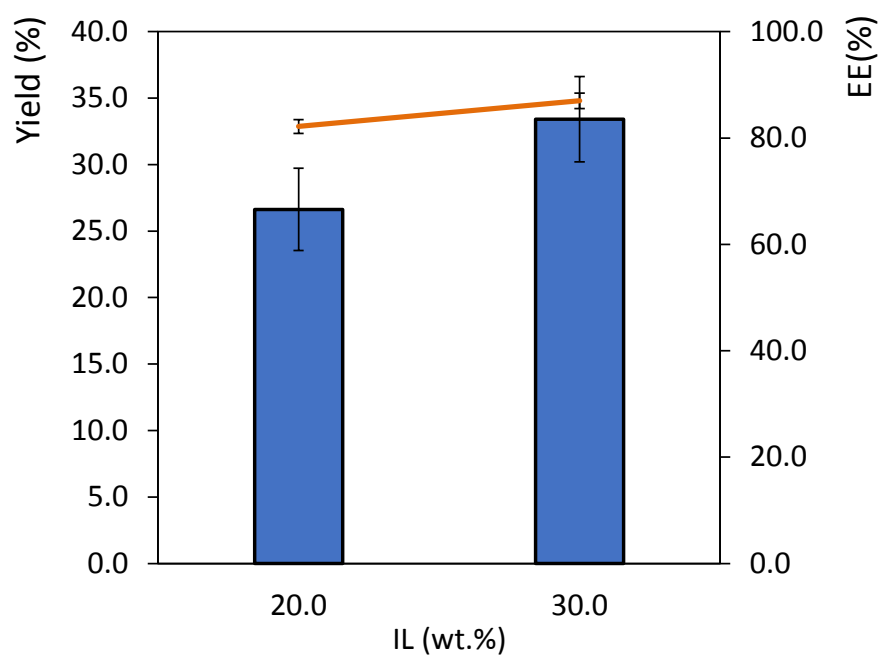

Figure S1. Furfural yield (bars) and extraction eficiency, EE (dots) in the ABS at different IL concentrations (wt.\%). The $\mathrm{HCl}$ concentration is fixed at $5 \mathrm{wt} . \%$ and the temperature at $120{ }^{\circ} \mathrm{C}$.

The results attained in these initial assays highlight the importance of the IL wt.\% in furfural yield. On the other hand, temperature and reaction time display an important role in furfural yield. In this sense, we studied the temperatures of 120 and $130{ }^{\circ} \mathrm{C}$ at 2.5 and $3.0 \mathrm{~min}$ of reaction time, with the fixed conditions of $5 \mathrm{wt} . \%$ of $\mathrm{HCl}$ and $30 \mathrm{wt} . \%$ of IL (Figure S2). It was observed that the yield increases significatively, for both tested reaction times, when the temperature increases up to $130{ }^{\circ} \mathrm{C}$. On the contrary, increasing the time does not influence the results at $120{ }^{\circ} \mathrm{C}$, but there is a sharp increase in furfural yield, from $46.3 \%$ to $60.3 \%$, at $130^{\circ} \mathrm{C}$. These results show the determining factor of temperature, since at $120{ }^{\circ} \mathrm{C}$ a plateau in yield was reached. Higher temperatures were also tested, beginning with $140{ }^{\circ} \mathrm{C}$ at 2.5 minutes time. However, it was visually apparent that some degradation was occurring, which was reflected in the yield attained (56.9\%). Therefore, a shorter reaction time was tested $(1.0 \mathrm{~min})$ with higher temperatures (140 and $\left.150{ }^{\circ} \mathrm{C}\right)$, attaining higher yields $(77.12 \%$ and $70.16 \%$, respectively). These last results reveal that a careful balance between temperature and time must be maintained, since a decrease in yield is observed when the temperature is increased after an established period of time, most likely due to furfural degradation. 


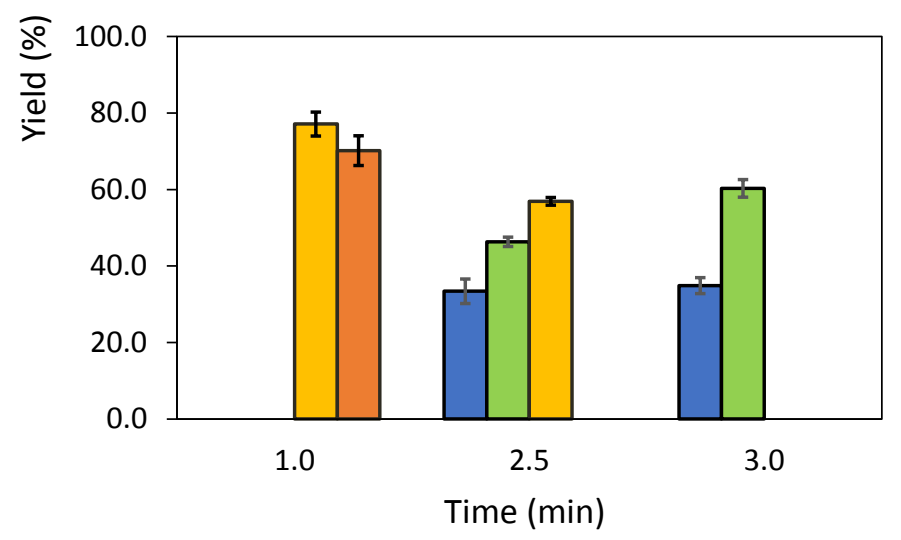

Figure S2. Furfural yield in the ABS at different temperatures $\left(\square 120^{\circ} \mathrm{C}, \square 130{ }^{\circ} \mathrm{C}, \square 140{ }^{\circ} \mathrm{C}\right.$, $\square 150{ }^{\circ} \mathrm{C}$ ) and reaction times. The $\mathrm{HCl}$ concentration is fixed at $5 \mathrm{wt} . \%$ and the IL concentration is fixed at $30 \mathrm{wt} . \%$. 


\section{Process optimization - response surface methodology (RSM)}

In a $2^{\mathrm{k}}$ surface response methodology there are $k$ factors that contribute to a different response, and the data are treated according to a second order polynomial equation according to equation S1:

$$
y=\beta_{0}+\sum \beta_{i} X_{i}+\sum \beta_{i i} X_{i}^{2}+\sum_{i<j} \beta_{i j} X_{i} X_{j}
$$

where $y$ is the response variable and $\beta_{0}, \beta_{i}, \beta_{i i}$ and $\beta_{i j}$ are the adjusted coefficients for the intercept, linear, quadratic and interaction terms, respectively, and $X_{i}$ and $X_{j}$ are independent variables. This model allows the drawing of surface response curves and through their analysis the optimal conditions can be determined. ${ }^{1}$ The $2^{3}$ factorial planning has been defined by the central point (zero level), the factorial points ( 1 and -1 , level one) and the axial points (level $\alpha$ ) The axial points are encoded at a distance $\alpha$ from the central point, according to equation S2:

$$
\alpha=\left(2^{k}\right)^{1 / 4}
$$

Table S2. $2^{3}$ factorial planning.

\begin{tabular}{c|ccc}
\hline Experiment & $\chi_{1}$ & $\chi_{2}$ & $\chi_{3}$ \\
\hline $\mathbf{1}$ & -1 & -1 & -1 \\
$\mathbf{2}$ & 1 & -1 & -1 \\
$\mathbf{3}$ & -1 & 1 & -1 \\
$\mathbf{4}$ & 1 & 1 & -1 \\
$\mathbf{5}$ & -1 & -1 & 1 \\
$\mathbf{6}$ & 1 & -1 & 1 \\
$\mathbf{7}$ & -1 & 1 & 1 \\
\cline { 2 - 3 }
\end{tabular}




\begin{tabular}{c|ccc}
\hline 8 & 1 & 1 & 1 \\
9 & -1.68 & 0 & 0 \\
10 & 1.68 & 0 & 0 \\
11 & 0 & -1.68 & 0 \\
12 & 0 & 1.68 & 0 \\
13 & 0 & 0 & -1.68 \\
14 & 0 & 0 & 1.68 \\
15 & 0 & 0 & 0 \\
16 & 0 & 0 & 0 \\
17 & 0 & 0 & 0 \\
18 & 0 & 0 & 0 \\
19 & 0 & 0 & 0 \\
20 & 0 & 0 & 0 \\
\hline
\end{tabular}


Table S3. Coded levels of independents variables used in the first and second factorial planning.

\begin{tabular}{lcccccc}
\hline & & \multicolumn{5}{c}{ Level } \\
\cline { 3 - 7 } $\begin{array}{l}\text { Studied } \\
\text { parameters }\end{array}$ & Symbol & Axial & Factorial & Central & Factorial & Axial \\
& & -1.68 & -1 & 0 & 1 & 1.68 \\
\hline $\mathbf{H C l}(\mathbf{w t . \% )}$ & $\mathrm{HCl}$ & 0.8 & 2.5 & 5.0 & 7.5 & 9.2 \\
Temperature $\left({ }^{\circ} \mathrm{C}\right)$ & $\mathrm{T}$ & 123.20 & 130.0 & 140.0 & 150.0 & 156.8 \\
$\mathrm{IL}(\mathbf{w t . \% )}$ & $\mathrm{IL}$ & 13.2 & 20.0 & 30.0 & 40.0 & 46.8 \\
\hline
\end{tabular}


Table S4. Regression coefficients of the predicted second-order polynomial model from factorial planning for the dependable variable of furfural yield.

\begin{tabular}{|c|c|c|c|c|}
\hline & $\begin{array}{l}\text { Regression } \\
\text { coefficients }\end{array}$ & $\begin{array}{l}\text { Standard } \\
\text { deviation }\end{array}$ & t-student (10) & P-value \\
\hline Interception & 58.1395 & 2.4101 & 24.1234 & $<0.05$ \\
\hline $\mathrm{HCl}$ & 12.2640 & 3.1997 & 3.8328 & $<0.05$ \\
\hline $\mathrm{HCl}^{2}$ & -20.7994 & 3.1184 & -6.6698 & $<0.05$ \\
\hline Temperature & 16.9536 & 3.1997 & 5.2985 & $<0.05$ \\
\hline Temperature $^{2}$ & -9.1409 & 3.1184 & -2.9312 & $<0.05$ \\
\hline IL & 7.3026 & 3.1997 & 2.2822 & $<0.05$ \\
\hline IL $^{2}$ & -3.58304 & 3.1184 & -1.1490 & 0.2773 \\
\hline $\mathrm{HCl} \times$ Temperature & -21.7383 & 4.1787 & -5.2021 & $<0.05$ \\
\hline $\mathrm{HCl} \times \mathrm{IL}$ & -12.0796 & 4.1787 & -2.8907 & $<0.05$ \\
\hline IL $\times$ Temperature & -3.9928 & 4.1787 & -0.9555 & 0.3618 \\
\hline
\end{tabular}


Table S5. Regression coefficients of the predicted second-order polynomial model from factorial planning for the dependable variable of $\mathrm{D}$ factor.

\begin{tabular}{|c|c|c|c|c|}
\hline & $\begin{array}{l}\text { Regression } \\
\text { coefficients }\end{array}$ & $\begin{array}{l}\text { Standard } \\
\text { deviation }\end{array}$ & t-student (10) & P-value \\
\hline Interception & 5.0928 & 0.54758 & 9.3006 & $<0.05$ \\
\hline $\mathrm{HCl}$ & -0.3363 & 0.72698 & -0.9252 & 0.37664 \\
\hline $\mathrm{HCl}^{2}$ & -1.0352 & 0.70852 & -2.9222 & $<0.05$ \\
\hline Temperature & 1.0722 & 0.72698 & 2.9497 & $<0.05$ \\
\hline Temperature ${ }^{2}$ & 0.0597 & 0.70852 & 0.1686 & 0.86946 \\
\hline IL & 1.8782 & 0.72698 & 5.1671 & $<0.05$ \\
\hline IL $^{2}$ & 0.0318 & 0.70852 & 0.0899 & 0.93012 \\
\hline $\mathrm{HCl} \times$ Temperature & -1.3796 & 0.94943 & -2.9060 & $<0.05$ \\
\hline $\mathrm{HCl} \times \mathrm{IL}$ & -0.5885 & 0.94943 & -1.2396 & 0.24340 \\
\hline IL $\times$ Temperature & -0.5834 & 0.94943 & -1.2290 & 0.24719 \\
\hline
\end{tabular}




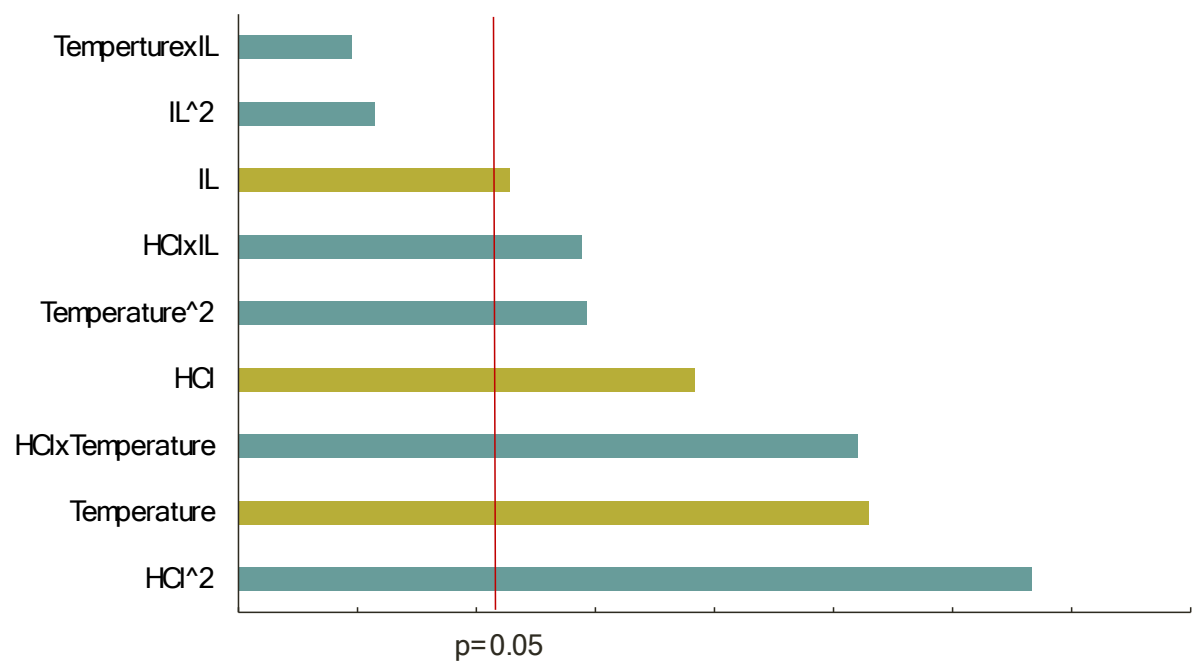

Figure S3. Pareto chart for the standardized main effects (positive ( $\square$ ) and negative ( $\square)$ ) in the factorial planning for furfural yield optimization. Vertical line indicates the statistical significance of the effects. 

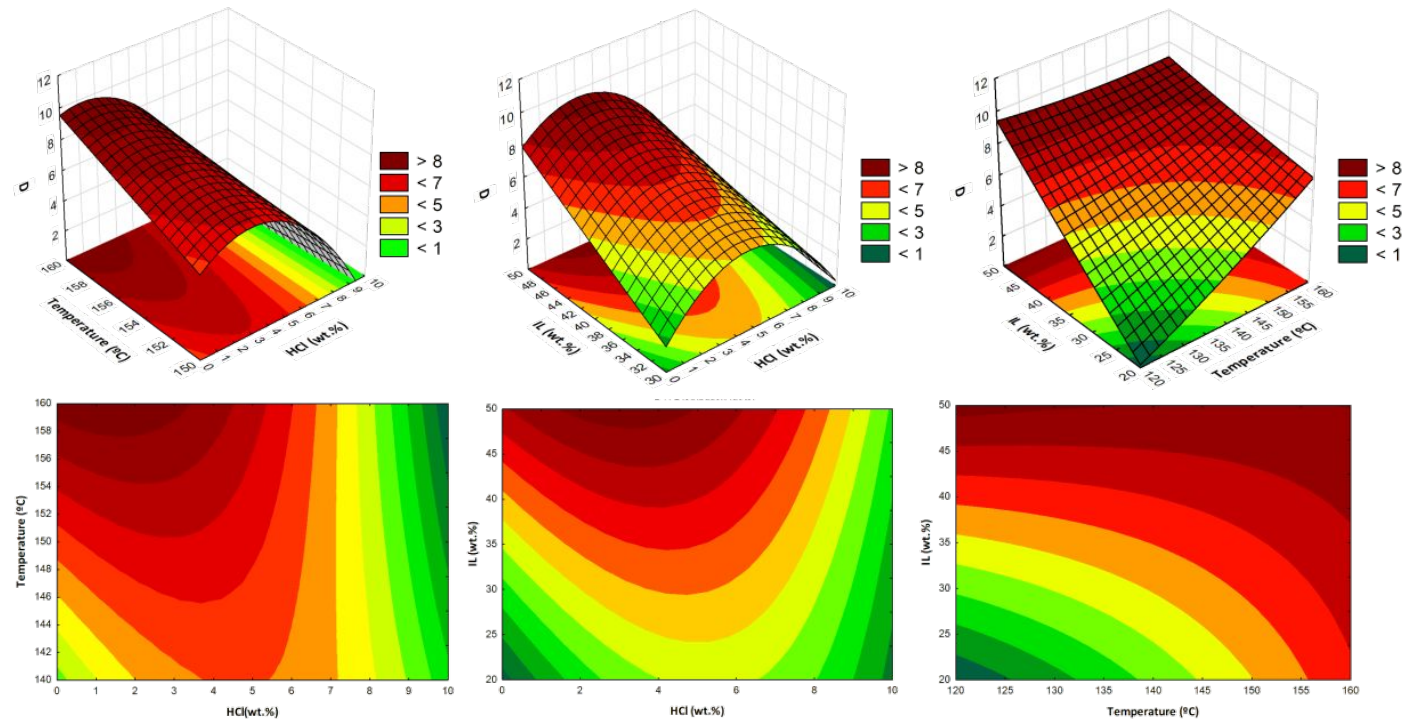

Figure S4. Response surface (top) and contour plots (bottom) of the distribution factor (D) using a biphasic system with $\left[\mathrm{P}_{444(14)}\right] \mathrm{Cl}$ with the combined effects of: (i) temperature and $\mathrm{HCl}$ concentration; (ii) IL and $\mathrm{HCl}$ concentrations; and (iii) IL concentration and temperature. 


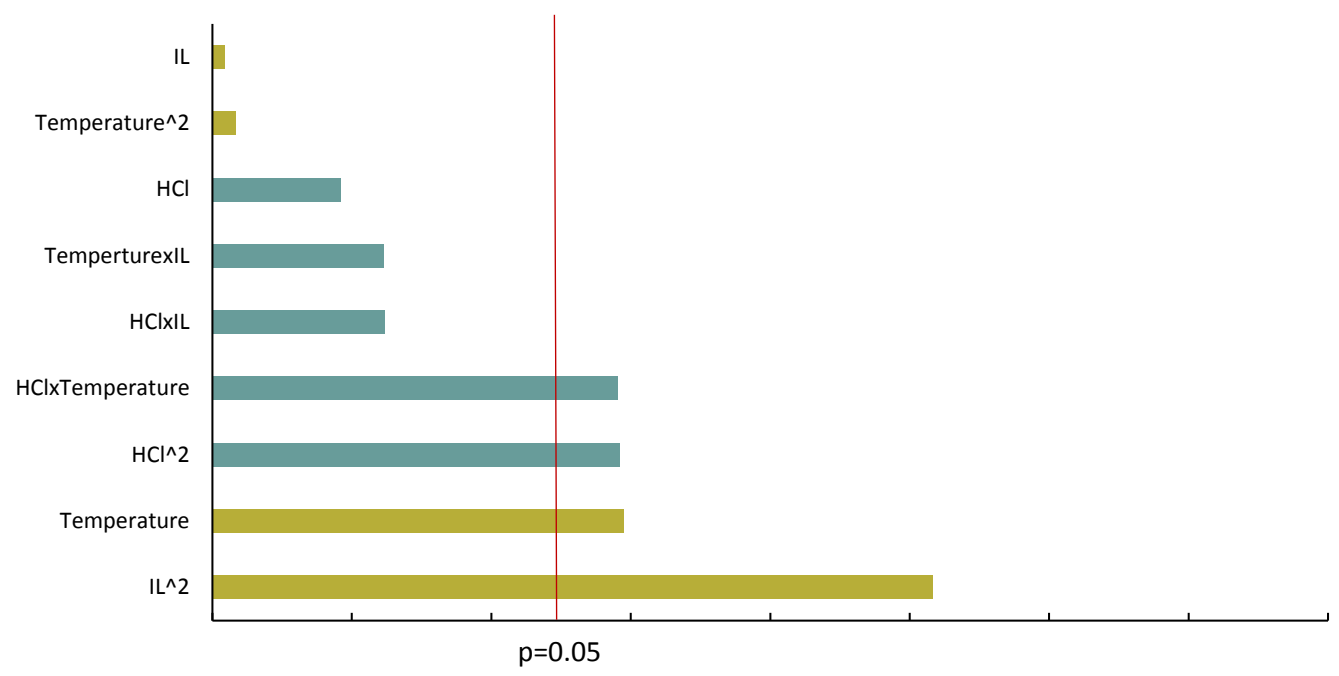

Figure S5. Pareto chart for the standardized main effects (positive ( $\square)$ and negative ( $\square)$ ) in the factorial planning for the $\mathrm{D}$ factor optimization. Vertical line indicates the statistical significance of the effects. 


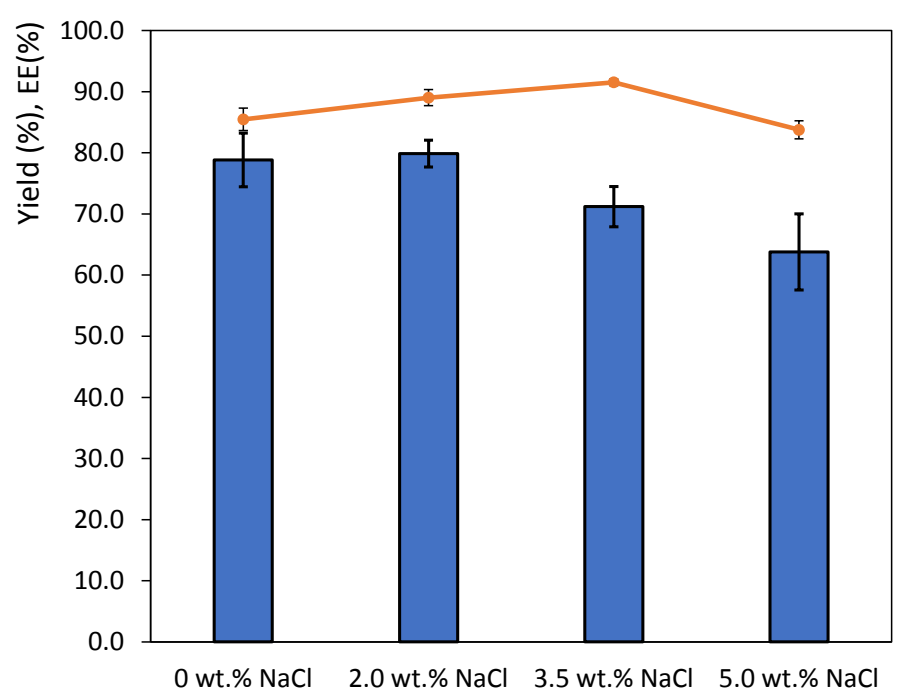

Figure S6. Furfural yield (bars) and extraction eficiency (dots) in the ABS. The values in the X axis correspond to the concentration of $\mathrm{NaCl}$ that substituted the fixed concentration of 6.5 wt. $\%$ of $\mathrm{HCl}$. The assays were conducted in the fixed conditions of $140{ }^{\circ} \mathrm{C}$ and $30 \mathrm{wt} . \%$ of IL. 


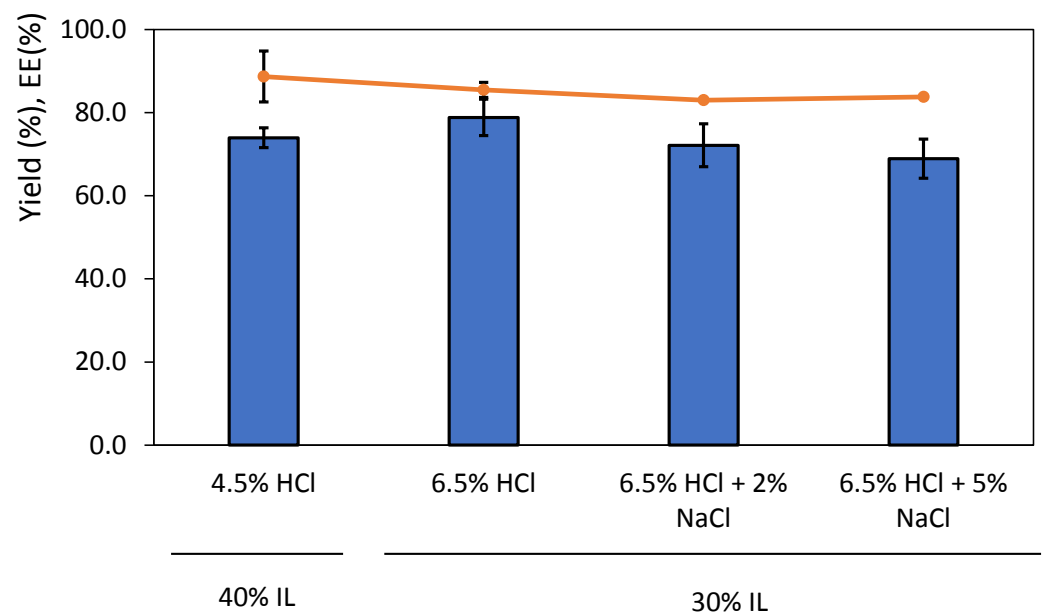

Figure S7. Furfural yield (bars) and extraction eficiency (dots) in the ABS. Assays were conducted at the fixed temperature of $140{ }^{\circ} \mathrm{C}$. $\mathrm{NaCl}$ was added to the $\mathrm{HCl}$ concentration in the ABS. 
${ }^{1} \mathrm{H}$ Pure IL
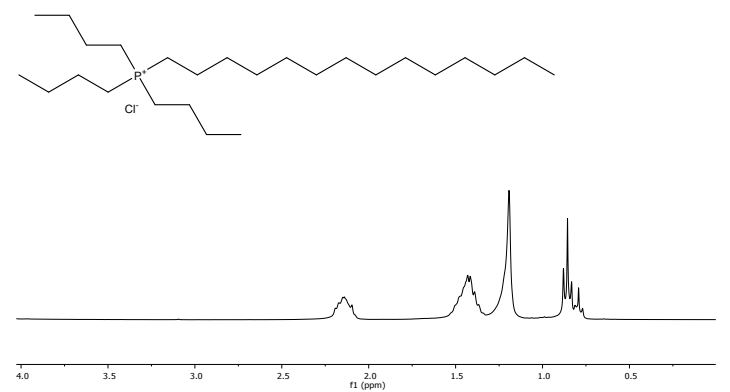

${ }^{1} \mathrm{H}$ Recoved IL
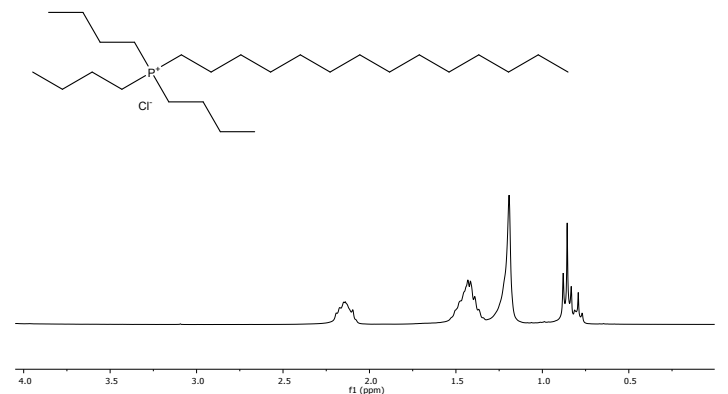

4.
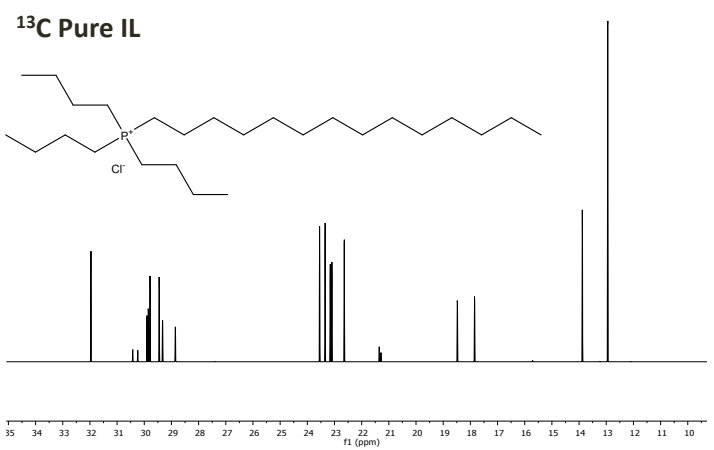

${ }^{13} \mathrm{C}$ Recovered IL
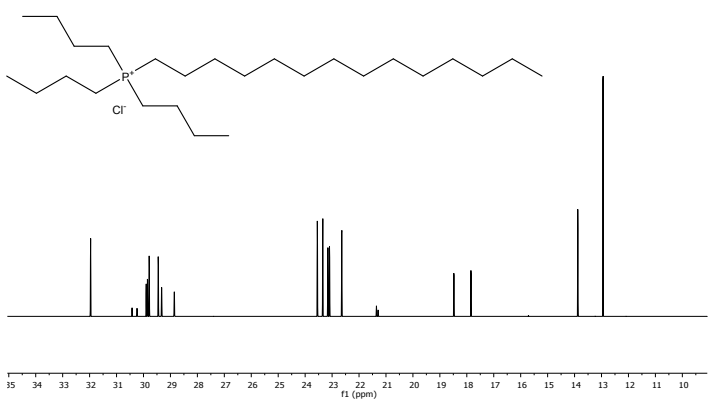

Figure S8. ${ }^{1} \mathrm{H}$ and ${ }^{13} \mathrm{C}$ NMR spectra of the pure and recovered IL. 
${ }^{1} \mathrm{H}$ Recovered IL

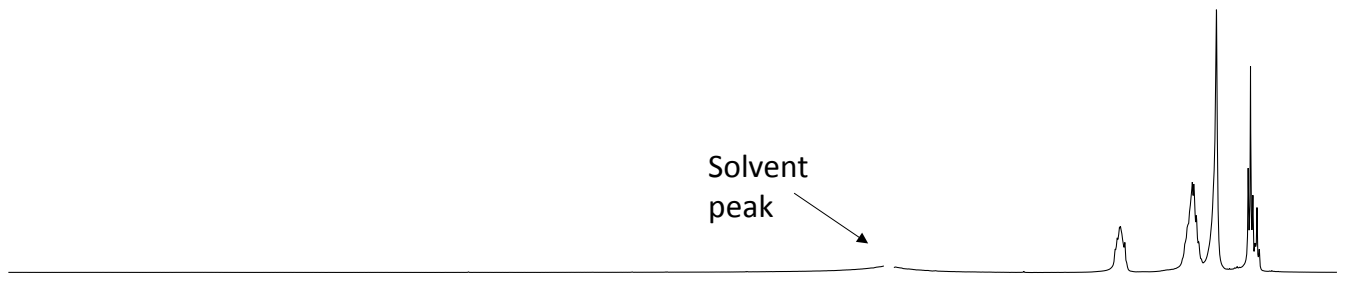

$\begin{array}{lllllllllllllllllllllllllllllll}13.5 & 13.0 & 12.5 & 12.0 & 11.5 & 11.0 & 10.5 & 10.0 & 9.5 & 9.0 & 8.5 & 8.0 & 7.5 & 7.0 & 6.5 & 6.0 & 5.5 & 4.0 & 3.5 & 3.0 & 2.5 & 2.0 & 1.5 & 1.0 & 0.5\end{array}$ ${ }^{13} \mathrm{C}$ Recovered IL

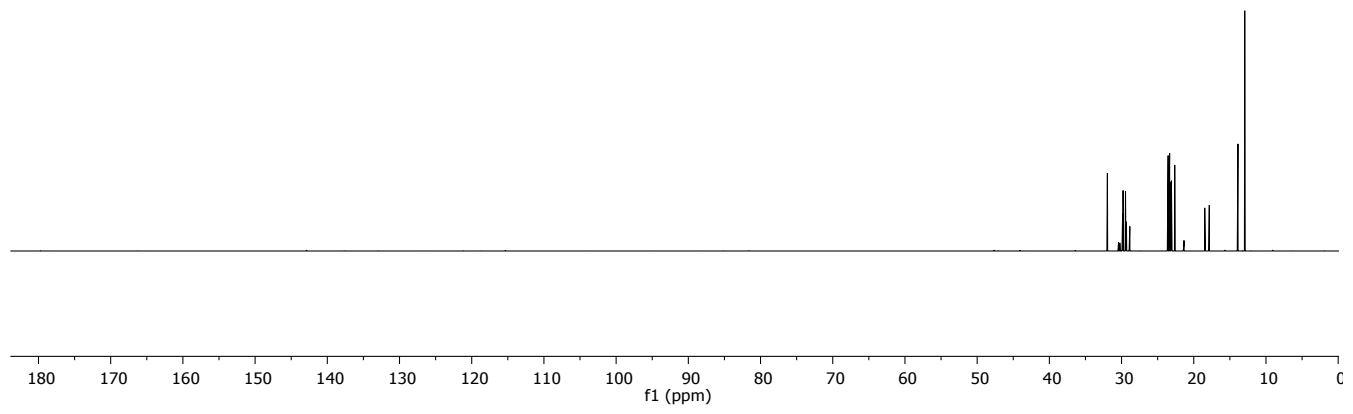

Figure S9. Full ${ }^{1} \mathrm{H}$ and ${ }^{13} \mathrm{C}$ NMR spectra of the recovered IL. 

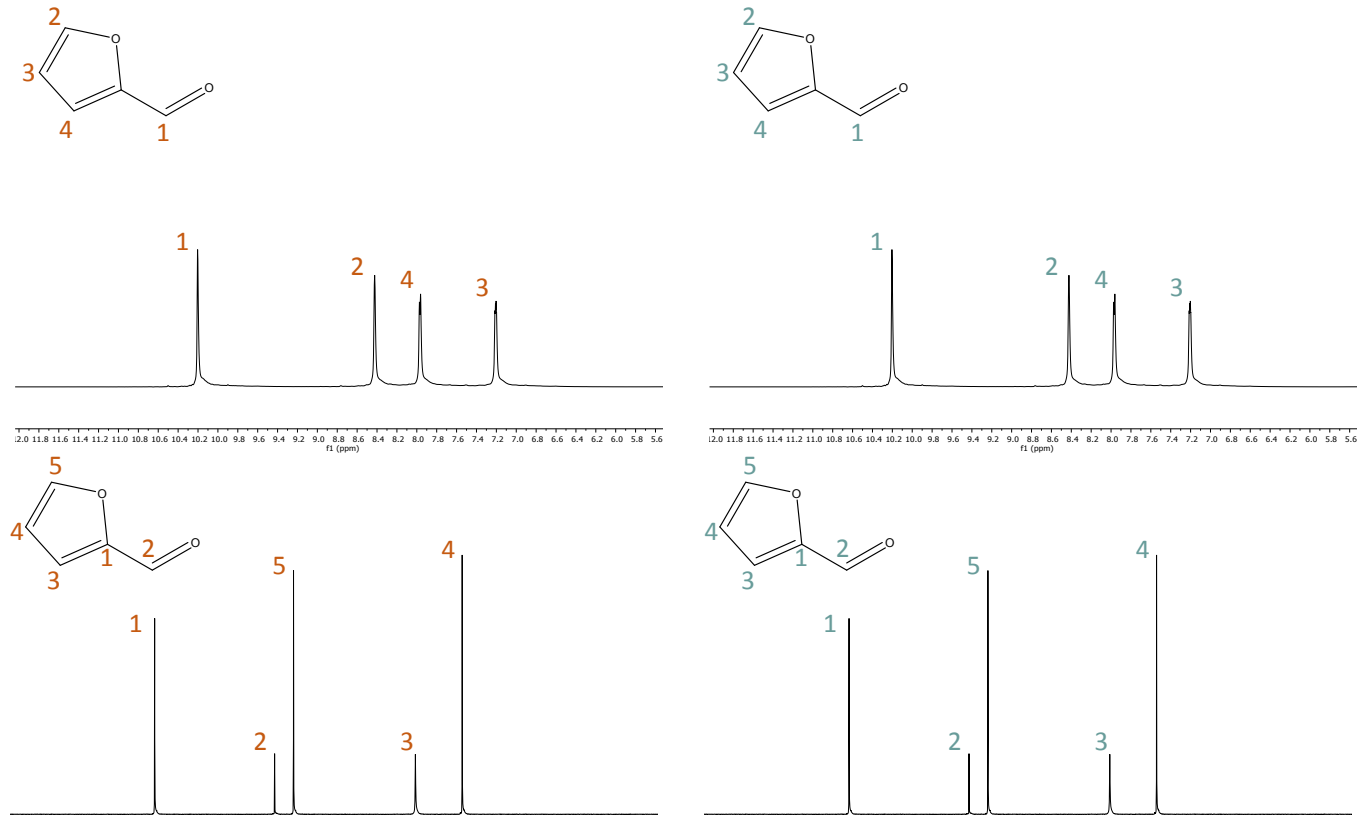

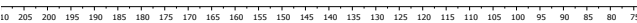

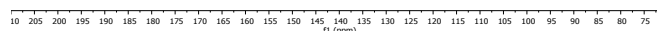

Figure S10. ${ }^{1} \mathrm{H}$ and ${ }^{13} \mathrm{C}$ NMR of standard (left) and recovered furfural (right). 

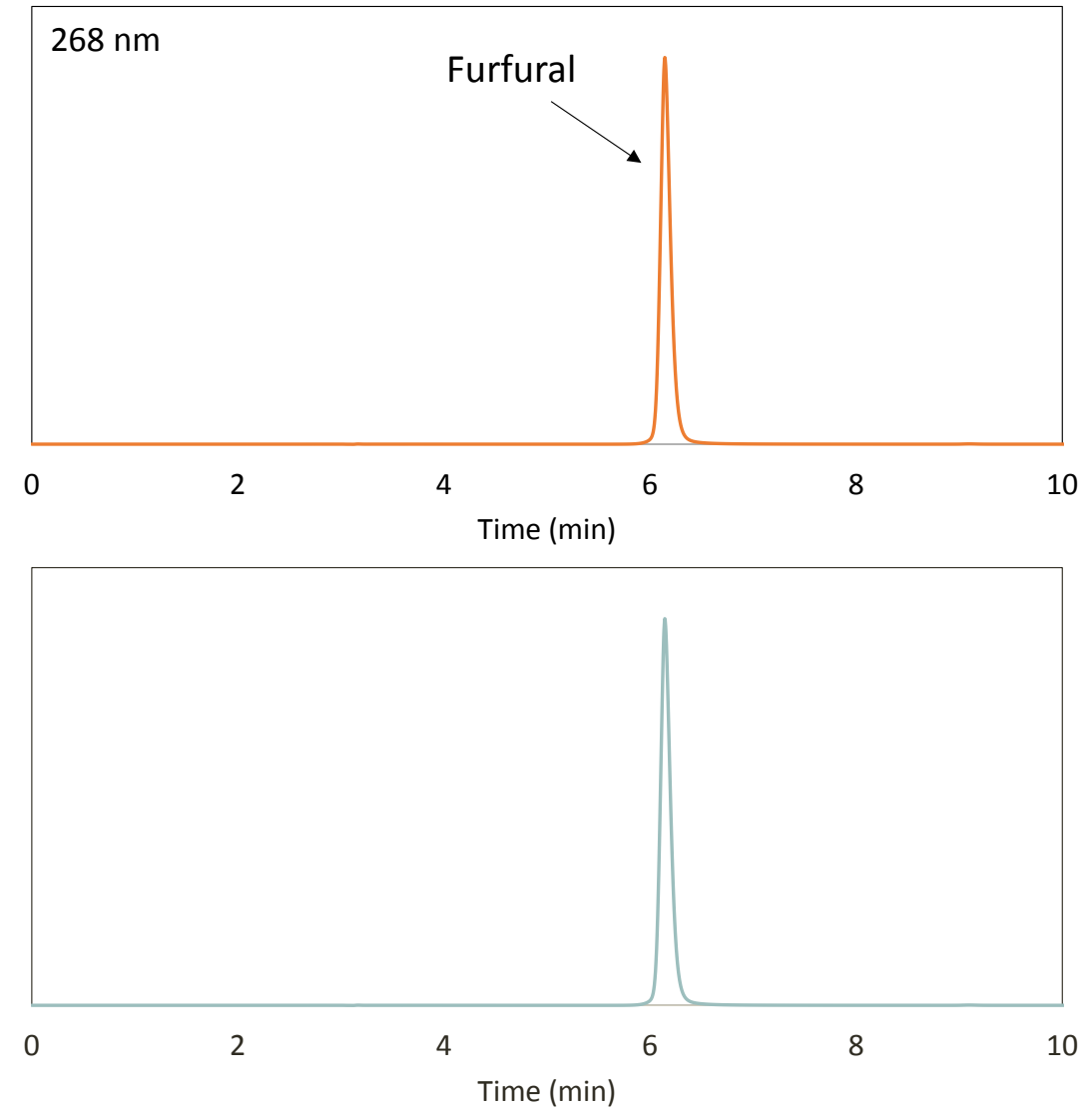

Figure S11. HPLC chromatogram at $268 \mathrm{~nm}$ of the standard (top) and recovered furfural (bottom). 


\section{References}

(1) Khuri, A. I.; Mukhopadhyay, S. Response Surface Methodology. Wiley Interdiscip. Rev. Comput. Stat. 2010, 2 (2), 128-149. https://doi.org/10.1002/wics.73. 